\title{
Farid Ud-Din `Attâr, Le langage des oiseaux (Manteq ut-Tayr)
}

Préface de Mohammad Reza Shafi'i Kadkani.

Paris, Éditions du Cerf, coll. « Patrimoines - Islam », 2012, 512 p.

\section{Mustapha Naïmi}

\section{(2) OpenEdition}

Journals

Édition électronique

URL : http://journals.openedition.org/assr/26591

DOI : 10.4000/assr.26591

ISSN : $1777-5825$

Éditeur

Éditions de l'EHESS

Édition imprimée

Date de publication : 31 décembre 2014

Pagination : 312

ISBN : 978-2-7132-2467-6

ISSN : 0335-5985

Référence électronique

Mustapha Naïmi, "Farid Ud-Din `Attâr, Le langage des oiseaux (Manteq ut-Tayr) », Archives de sciences sociales des religions [En ligne], 168 | 2014, mis en ligne le 22 mai 2015, consulté le 22 septembre 2020. URL : http://journals.openedition.org/assr/26591 ; DOI : https://doi.org/10.4000/assr.26591

Ce document a été généré automatiquement le 22 septembre 2020.

(c) Archives de sciences sociales des religions 


\section{Farid Ud-Din `Attâr, Le langage des oiseaux (Manteq ut-Tayr)}

Préface de Mohammad Reza Shafi'i Kadkani.

Paris, Éditions du Cerf, coll. « Patrimoines - Islam », 2012, 512 p.

Mustapha Naïmi

\section{RÉFÉRENCE}

Farid Ud-Din `Attâr, Le langage des oiseaux (Manteq ut-Tayr), Préface de Mohammad Reza Shafi'i Kadkani, Paris, Éditions du Cerf, coll. « Patrimoines - Islam », 2012, 512 p. 
1 Il s'agit d'une nouvelle traduction fondée sur l'édition critique persane établie à partir des manuscrits les plus anciens. C'est une œuvre poétique remontant au $\mathrm{XIII}^{\mathrm{e}}$ siècle d'un des plus grands soufis persans de la Perse médiévale. Manteq utTayr est attribué à Farid ud-Din Mohammad ibn Ibrâhim `Attâr (553-627 AH / 1174 / 1248 AD) qui occupe une place particulière au côté du Mathnavi spirituel, de Jalâl ud-Din Balkhi-Rumî. Il s'agit d'une élaboration poétique comprenant 4729 distiques (beyt) qui s'inscrit dans les deux traditions portant la mention de Manteq: l'une philosophique (Manteq ut-Tuyur d'Avicenne et Risâlat ut-Tayr d'Ahhmad Ghazzâli) et l'autre poétique (Manteq utTayr de Sanâ' i et de Khâqâni). L'œuvre fut probablement achevée en 1229 de l'ère

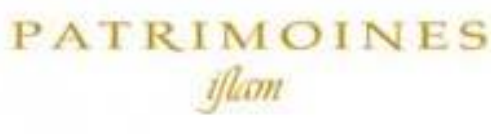

FARID UD-DIN 'ATTÂR le langage des oiseaux Manteq ut-Tayr

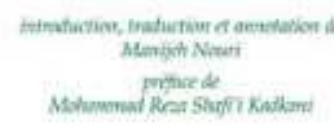
chrétienne. H. Ritter résume ainsi cette histoire des trente oiseaux partis à la recherche de l'oiseau fabuleux Simorgh.

2 Le langage des oiseaux (Manteq ut-Tayr) se situe parmi les ouvrages allégoriques et mystiques de la littérature persane. Le langage des oiseaux a été célébré par les poètes Rumi et Hâfed ainsi que par les peintres et les calligraphes; et il a été illustré par les enlumineurs, décorant, embellissant les manuscrits, témoignant ainsi de l'importance de cette œuvre dans le monde iranien et musulman chiite. Au cours du XIX et $\mathrm{Xx}^{\mathrm{e}}$ siècles, le Manteq ut-Tayr a été traduit dans plusieurs langues européennes, comme le français, l'anglais, l'allemand, l'italien, bien que toute l'ampleur et la richesse poétique et mystique d'un écrit persan du XIII $^{\mathrm{e}}$ siècle ne puissent être exprimées dans une traduction.

3 La recherche de l'Un-absolu est illustrée par le voyage des oiseaux partis en quête de Simorgh, leur mystérieux roi. Ils traversent maintes épreuves symbolisées par diverses vallées. En chacun de ces lieux, il leur est demandé de sacrifier un des aspects de leur être avant d'abandonner leur Soi le plus profond. Telle est la condition nécessaire pour atteindre le but de recherche consciemment. Les oiseaux arrivent au sommet de la montagne Qâf, là où le roi Simogh les accueille et leur apprend qu'il est leur miroir comme ils sont le sien. C'est alors que commence la quête véritable.

Les copies manuscrites du Manteq dépassent le chiffre de 500. C'est une œuvre qui a assez attiré l'attention des orientalistes occidentaux pour qu'en 1857 et 1863 nous soit donnée une traduction complète réalisée par Joseph Héliodore Sagesse Vertu Gracin de Tassy. Dans sa lecture, l'éditeur s'est attaché à restituer les sens des termes d'origine, évoquant les sources historiques et les difficultés qui caractérisent les manuscrits irrespectueux des règles littéraires et linguistiques de cette époque. Le Manteq serait comme une œuvre isolée, comme s'il n'y avait pas de relations avec les traités et la pensée théologique manifeste. Dès lors, le lexique proposant l'interprétation de tel ou tel terme doit prendre en compte l'ensemble de l'œuvre. 
5 Au cours de ces deux derniers siècles, les savants orientalistes européens se sont passionnés pour l'œuvre de 'Attâr, et particulièrement pour le Langage des oiseaux. Parmi eux, Garcin de Tassy, Hellmut Ritter, Louis Massignon, Reynold A. Nicholson ont traduit ou présenté le Langage des oiseaux, manifestant ainsi tout l'intérêt qu'ils portent à l'œuvre.

6 La présente traduction en français, réalisée par Manijeh Nouri et préfacée par Mohammad Reza Shafi'i Kadkani à l'Institute for Advanced Study (Princeton - ÉtatsUnis) sur une édition critique scientifique à partir d'innombrables manuscrits, permettra au lecteur de suivre le déroulement du texte, distique par distique, en bénéficiant de notes substantielles éclairant les particularités lexicales propres au langage de `Attâr.

7 Mohammad Reza Shafi'i Kadkani a été durant des années témoin des efforts de la traductrice, de ses recherches non seulement sur l'auteur, mais aussi sur le langage des mystiques persans. En établissant l'édition critique des œuvres principales de `Attâr, Manijeh Nouri consacre une part importante à la littérature poétique persane; elle couronne nombre d'années de recherche et de patients efforts qui ont contribué à faire connaître un chef-d'œuvre de la littérature mondiale dans sa langue d'origine telle que nous la donne cette traduction nouvelle. 